\title{
Computability in Europe 2008
}

\author{
Arnold Beckmann • Costas Dimitracopoulos • \\ Benedikt Löwe
}

Received: 17 November 2009 / Accepted: 19 November 2009 / Published online: 5 December 2009 (C) The Author(s) 2009. This article is published with open access at Springerlink.com

The seven papers in this special issue arose from the conference CiE 2008: Logic and Theory of Algorithms, held at the University of Athens in June 2008. CiE 2008 was the forth of a new series of conferences associated with the interdisciplinary network Computability in Europe.

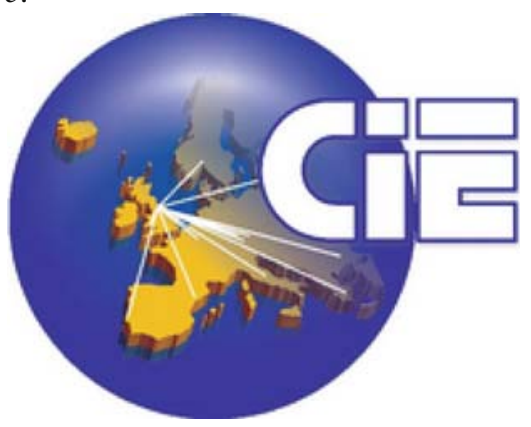

\footnotetext{
A. Beckmann $(\varangle)$

Department of Computer Science, Swansea University,

Singleton Park, Swansea SA2 8PP, UK

e-mail: a.beckmann@swansea.ac.uk

C. Dimitracopoulos

Department of History and Philosophy of Sciences (M.I.Th.E.), National and Kapodistrian University of Athens, University Campus, Ano Ilisia, 15771 Athens, Greece

e-mail: cdimitr@phs.uoa.gr

B. Löwe

Institute for Logic, Language and Computation, Universiteit van Amsterdam, Postbus 94242, 1090 GE Amsterdam, The Netherlands

e-mail: bloewe@science.uva.nl

B. Löwe

Department Mathematik, Universität Hamburg, Bundesstrasse 55, 20146 Hamburg, Germany
} 
Computability in Europe (CiE) used to be an informal network of European scientists working on computability theory, including its foundations, technical development, and applications-mainly identified by its successful conference series with meetings in Amsterdam (2005), Swansea (2006), and Siena (2007). During the conference in Athens in 2008, this informal network constituted itself as the Association for Computability in Europe at the annual general meeting on 16 June 2008.

The object of the Association is to promote the development, particularly in Europe, of computability-related science, ranging over mathematics, computer science, and applications in various natural and engineering sciences such as physics and biology. This object also includes the promotion of the study of philosophy and history of computing as it relates to questions of computability. Apart from the conference series, the Association established a publications committee and first steps towards setting up a book series have been taken. After our conference in Athens 2008, we reconvened in Heidelberg (2009), and further conferences have been planned in Ponta Delgada (Açores, Portugal; 2010), Sofia (Bulgaria; 2011), and Cambridge (England; 2012). The 2012 meeting will be part of the celebrations of the centenary of Alan Turing's birth in the United Kingdom.

$\mathrm{CiE} 2008$ aimed at bridging the gap from the logical methods of mathematical and meta-mathematical flavour to the applied and industrial questions that are involved in devising and choosing the right algorithms and analysing their effectiveness and efficiency. The conference was an interdisciplinary venue for researchers from computer science and mathematics to exchange ideas, approaches and techniques in their respective work, thereby generating a wider community for work on new computational paradigms that allows uniform approaches to diverse areas, the transformation of theoretical ideas into applicable projects, and general cross-fertilization transcending disciplinary borders. As is usual in computer science, CiE 2008 had a regular pre-proceedings volume published in the Lecture Notes in Computer Science:

Arnold Beckmann, Costas Dimitracopoulos, and Benedikt Löwe (eds.), Logic and Theory of Algorithms, Fourth Conference on Computability in Europe, CiE 2008, Athens, Greece, June 2008, Proceedings, Heidelberg 2008 [Lecture Notes in Computer Science 5028].

As a follow-up to the conference, the organizers of CiE 2008 have also prepared post-conference publications. Three special issues of journals are being edited with journal versions of talks and presentations at $\mathrm{CiE}$ 2008. Our publication policy does not allow double publications of the same research content: in order to get accepted for a post-proceedings special issue, a journal version of a talk must exhibit unpublished research content beyond the content printed in the LNCS volume.

This special issue of the Journal Archive for Mathematical Logic is one of the postconference publication. The special issue underwent a thorough and strict refereeing process. After CiE 2008, we invited fourteen authors to submit a journal version of their paper to the special issue; in the end, we accepted the seven papers that the reader can find in this volume.

The selection procedure was the work of many referees who put in a lot of work to ascertain the quality of the special issue. 
The paper by Rosalie Iemhoff is a paper related to her plenary talk at CiE 2008. The paper by De Mol and Bullynck represents the special session on Algorithms in the History of Mathematics (organized by Jens Høyrup and Karine Chemla) at CiE 2008. The remaining five papers are full versions of contributed talks; two of those (Liu/Wu, Soskova) have a short version published in the mentioned LNCS preproceedings volume.

For the most current information about the conference series CiE-CS, we refer the reader to our webpage, http://www.illc.uva.nl/CiE/.

Acknowledgments We would like to thank all our referees for their help in producing this special issue, including the members of the CiE 2008 Programme Committee. We are delighted to acknowledge and thank the following for their essential financial support: City of Athens, Bank of Greece, Graduate Program in Logic, Algorithms and Computation (MPLA), Hellenic Ministry of Education, John S. Latsis Foundation, Kleos S.A., National and Kapodistrian University of Athens, Public Power Corporation S.A., Rizareio Foundation, The Elsevier Foundation.

Open Access This article is distributed under the terms of the Creative Commons Attribution Noncommercial License which permits any noncommercial use, distribution, and reproduction in any medium, provided the original author(s) and source are credited. 